\title{
Lignosulfonate/APP IFR and its flame retardancy in lignosulfonate- based rigid polyurethane foams
}

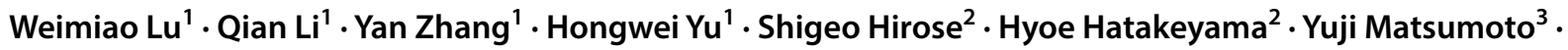 \\ Zhenfu Jin ${ }^{1}$
}

Received: 9 August 2017 / Accepted: 22 December 2017 / Published online: 7 February 2018

(c) The Japan Wood Research Society 2018

\begin{abstract}
Lignin containing substantial aromatic rings and high content of carbon has been employed as carbonizing agent to investigate the flame retardancy in the lignin/ammonium polyphosphate (APP) intumescent flame retardant (IFR) system. In addition, owing to the abundant phenolic and aliphatic hydroxyl groups, lignosulfonate, which is considered as a renewable aromatic macropolyols, substituted part of diethylene glycol (DEG) and copolymerized with isocyanate to produce lignosulfonatebased rigid polyurethane (LRPU) foams. Thermal stability was characterized by thermogravimetric analysis (TGA), and flame retardancy was investigated by limiting oxygen index (LOI) and cone calorimetry testing (CCT). Lignosulfonate increases thermal stability of LRPU foams and LRPU containing $15 \mathrm{wt} \%$ of lignosulfonate based on DEG $\left(\mathrm{L}_{15} \mathrm{RPU}\right)$ give rise to the best thermal stability. When $15 \%$ of lignosulfonate incorporated in the LRPU, reduced the heat release rate (HRR) and total heat release (THR) value $21 \mathrm{~kW} / \mathrm{m}^{2}$ and $13 \mathrm{MJ} / \mathrm{m}^{2}$, respectively, and postponed $96 \mathrm{~s}$ time-to-peak carbon monoxide production than that of pure DEG rigid polyurethane (RPU) foam, the LOI values increased progressively with lignosulfonate content increasing. These results showed that lignosulfonate polyol may substitute polyol to produce lignosulfonate-based RPU foam and the presence of lignosulfonate could improve the flame retardancy. The mass loss gradually decreases with increasing APP addition, and the highest char yield was obtained from LRPU5 foam which at the lignosulfonate-to-APP ratio is 1:5. At the lignosulfonate-to-APP ratio of 1:5, the LOI value increased over 30\%, and the HRR value reduced and the time-to-peak HRR postponed significantly. In addition, LRPU5 foams give rise to the lowest effect heat combustion (EHC) value, less smoke, and carbon monoxide $(\mathrm{CO})$ production. Lignosulfonate acts as carbonizing agent in the lignosulfonate/ APP IFR system, and the best fire retardancy is obtained at 1:5 of lignosulfonate-to-APP ratio.
\end{abstract}

Keywords Rigid polyurethane foam $\cdot$ Intumescent flame retardant $\cdot$ Lignosulfonate polyol $\cdot$ Carbonizing agent

Zhenfu Jin

jinzhenfuzj@126.com

1 Department of Wood Science and Technology, College of Engineering, School of Engineering, Zhejiang A \& F University, Linan, Hangzhou, Zhejiang 311300, China

2 Department of Environmental and Biological Chemistry, Fukui University of Technology, 3-6-1, Gakuen, Fukui, Fukui 910-8505, Japan

3 Graduate School of Agricultural and Life Sciences, the University of Tokyo, Yaoyi 1-1-1, Bunkyo-ku, Tokyo 113-8657, Japan

\section{Introduction}

Intumescent flame retardants (IFR) have attracted considerable attention in recent years due to its low toxicity, absence of dioxins, and low smoke production in fire accidents. In addition, IFR is halogen-free, which is considered to be eco-friendly and safe for the environment and ecosystem [1, 2]. In general, the intumescent formulations contain three main ingredients, namely, an acidic source, a carbonization agent compound, and a blowing agent $[3$, 4]. In spite of the considerable number of intumescent systems developed in the past years, the typical and widely studied IFR system is ammonium polyphosphate (APP) and pentaerythritol (PER) [3, 5]. APP is known to be preferred over other flame retardants due to its high amounts of phosphorus $(\mathrm{P})$ and nitrogen $(\mathrm{N})$, thermal stability and 
smaller loading, and a lower cost, excellent processing ability $[3,4]$. The acidic source is usually a $\mathrm{P}$ derivative, in most cases APP. APP is also believed to be served as a blowing agent in the intumescent formulation as a part of the ammonia and water emitted during pyrolysis $[3,5]$. Therefore, APP could act as the acidic source and blowing agent at the same time during combustion $[4,5]$. The carbonization agent usually employed polyhydric alcohols which is easily degraded by acid [5].

Lignin is three-dimensional amorphous biopolymer composed of phenylpropanoid units linked by ether and carbon-carbon bonds [6]. Because of its aromatic and carbon-carbon bonds structural characteristics, lignin exhibits high thermal stability, and its carbon-carbon and aromatic chemical structure results in a very high char residue during combustion [6-8]. The feature is a basic aspect of flame retardant additives, since char reduces the combustion rate of polymeric materials [9]. Lignin was reported to be a fire retardant of polyethylene terephthalate (PET) [10], polypropylene (PP) [11], acrylonitrile butadiene styrene copolymer (ABS) [12], and poly3-hydroxybutyrate (PHB) [13].

Owing to the presence of phenolic and aliphatic hydroxyl groups, and its aromatic characteristics, lignin can be considered as an aromatic macropolyol and can convert in a polyol precursor in the rigid polyurethane (RPU) foam synthesis [14-16].

At present, industrial lignin produced on a large scale is sodium lignosulfonate (LS), Kraft lignin (KL), solvolys lignin (SL), and hydrolysis lignin (HL), and those industrial lignins are used for preparation of green polyurethanes and composites [14]. In China, LS, which is obtained by sulfite pulping process, is easily available on a large scale. Lignin sulfonate is used as additives or as dispersants.

In this study, lignosulfonate was used to substitute part of fossil resources polyols and employed as carbonization agent and to investigate the effects of lignosulfonate content and the combination with APP on the thermal properties and flame retardancy of lignosulfonate-based rigid polyurethane (LRPU) foams.

\section{Materials and methods}

\section{Materials}

Diethylene glycol (DEG), methylene diphenyl diisocyanate (MDI-200, NCO $=32 \%$ ), di- $n$-butyltindilaurate (DBTDL), silicon oil, methyl phosphonate (DMMP), and APP, all reagent grade products, used without further purification. Lignosulfonate was a product of Yanbian Shixian Bailu Papermaking Co., Ltd.

\section{Preparation of lignosulfonate polyol}

Lignosulfonate was dispersed in DEG at $80^{\circ} \mathrm{C}$ for $2 \mathrm{~h}$ under constant stirring. After that the mixture was cooled to room temperature, then lignosulfonate polyol was finally obtained.

\section{LRPU foam}

Different wt $\%$ of lignosulfonate content LRPU foams were prepared as follows: blank (DEG), 5, 10, 15, 20, 25, and $30 \mathrm{wt} \%$ of lignosulfonate content were measured from the above lignosulfonate polyol. Lignosulfonate polyol was mixed with distilled water as the foaming agent, the catalyst, and the flame retardants (DMMP and APP) until homogenization, and then, MDI-200 was added into the mixture under continuous stirring. When it began to foam, the mixture was immediately poured into the mould. The obtained RPU foams without and with lignosulfonate designated as RPU and LRPU, and 5, 10, 15, 20, 25, and $30 \mathrm{wt} \%$ of lignosulfonate content were designated as $\mathrm{L}_{5} \mathrm{RPU}, \mathrm{L}_{10} \mathrm{RPU}, \mathrm{L}_{15} \mathrm{RPU}$, $\mathrm{L}_{20} \mathrm{RPU}, \mathrm{L}_{25} \mathrm{RPU}$, and $\mathrm{L}_{30} \mathrm{RPU}$, respectively.

Different ratio lignosulfonate and APP LRPU foams were prepared using $16.5 \mathrm{wt} \%$ of lignosulfonate polyol, and the other ingredients in the formulation were the same with different lignosulfonate content RPU foams. Lignosulfonate: APP was $1: 1,1: 2,1: 3,1: 4$, and 1:5 were designated as LRPU1, LRPU2, LRPU3, LRPU4, and LRPU5, respectively.

\section{Characterization}

\section{Thermogravimetric analysis (TGA)}

TGA was performed on a NETZSCH TG209 thermal analyzer (The NETZSCH Group, Germany). About $10 \mathrm{mg}$ of each sample was scanned from room temperature to $700{ }^{\circ} \mathrm{C}$ at a scanning rate of $10^{\circ} \mathrm{C} / \mathrm{min}$ under nitrogen gas at a flow rate of $50 \mathrm{~mL} / \mathrm{min}$.

\section{The limiting oxygen index (LOI) testing}

The LOI testing had been carried out on a JF-3 oxygen index instrument (Nanjing Jiangning Analytical Instrument Co., Ltd, China) according to GB/T 2406.2-2009 [17]. Samples $(120 \times 10 \mathrm{~mm}, 10 \mathrm{~mm}$ thick) were held vertically in an oxygen index measurement system.

\section{Cone calorimeter testing (CCT)}

CCT of RPU and LRPU foams was performed using an FTT UK cone calorimeter instrument (Stanton Redcroft Limited, UK) according to ISO5660-1:2015 [18] and 
ASTM E1354-16a standard [19]. Each RPU foam specimen $(100 \mathrm{~mm} \times 100 \mathrm{~mm} \times 25 \mathrm{~mm})$ was irradiated at a heat flux of $35 \mathrm{~kW} / \mathrm{m}^{2}$.

\section{Results and discussion}

\section{The effect of lignosulfonate contents on thermal decomposition of LRPU foams}

In this study, lignosulfonate contents ranging from 0 to $30 \mathrm{wt} \%$ were mixed with DEG to investigate the effect of lignosulfonate contents on thermal stability of LRPU foams. TGA measurements were performed to evaluate the thermal stability of these LRPU foams, and the corresponding results are presented in Fig. 1 and Table 1. RPU and LRPU foams show two steps thermal degradation in the $100-180^{\circ} \mathrm{C}$ range with maximum degradation temperature $\left(T_{\max 1}\right)$ around $140{ }^{\circ} \mathrm{C}$ and the $250-350{ }^{\circ} \mathrm{C}$ range with maximum degradation temperature $\left(T_{\max 2}\right)$ around $300{ }^{\circ} \mathrm{C}$, respectively (Fig. 1). The first step weight loss was less than 5\%, and may be due to evaporation of water and decomposition of low molecular compounds. The second degradation step weight loss account for more than $50 \%$ would be major decomposition step (Table 1). $T_{\max 2}$ of RPU foam from DEG was at $288{ }^{\circ} \mathrm{C}$, and $T_{\max 2}$ progressively shifted towards the higher temperature with an increasing in the amount of lignosulfonate in the sample. $T_{\max 2}$ of $\mathrm{L}_{15} \mathrm{RPU}$ appeared at $304{ }^{\circ} \mathrm{C}$, while further increasing lignosulfonate loading, there was no distinct difference at $T_{\max 2}$. It is noteworthy that mass loss was the lowest at $15 \%$ lignosulfonate content, and further increasing lignosulfonate loading the mass loss was increased more than $50 \%$, suggesting that the thermal stability of RPU foams is really affected by the presence of lignosulfonate, and the best dosage is $15 \%$ lignosulfonate loading.
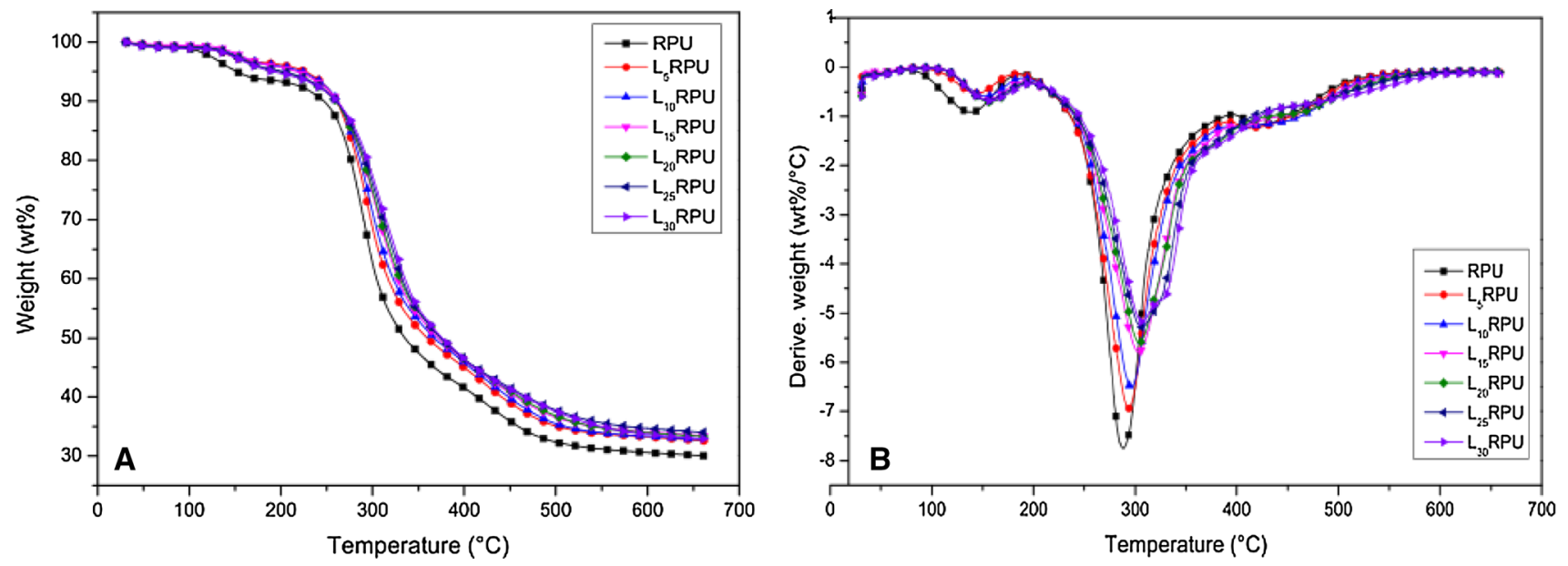

Fig. 1 TGA (a) and DTG (b) curves of RPU and LRPU foams in $\mathrm{N}_{2}$

Table 1 Detailed data of TGA measurements of RPU and LRPU foams

\begin{tabular}{lllllll}
\hline Sample & $\begin{array}{l}\text { Lignin contents } \\
(\%)\end{array}$ & $\begin{array}{l}T_{\operatorname{max1}}{ }^{\mathrm{a}} \\
\left({ }^{\circ} \mathrm{C}\right)\end{array}$ & $\begin{array}{l}\text { Mass loss } 1^{\mathrm{a}} \\
(\mathrm{wt} \%)\end{array}$ & $\begin{array}{l}T_{\max { }^{\mathrm{a}}} \\
\left({ }^{\circ} \mathrm{C}\right)\end{array}$ & $\begin{array}{l}\text { Mass loss2 }{ }^{\mathrm{a}} \\
(\mathrm{wt} \%)\end{array}$ & $\begin{array}{l}\mathrm{Char}_{700}{ }^{\circ}{ }^{\mathrm{a}} \\
(\mathrm{wt} \%)\end{array}$ \\
\hline $\mathrm{RPU}$ & 0 & 139 & 4.4 & 288 & 57.0 & 30.0 \\
$\mathrm{~L}_{5} \mathrm{RPU}$ & 5 & 144 & 1.4 & 294 & 58.4 & 32.5 \\
$\mathrm{~L}_{10} \mathrm{RPU}$ & 10 & 155 & 1.7 & 296 & 58.8 & 32.7 \\
$\mathrm{~L}_{15} \mathrm{RPU}$ & 15 & 155 & 1.6 & 304 & 32.7 & 33.4 \\
$\mathrm{~L}_{20} \mathrm{RPU}$ & 20 & 157 & 2.2 & 305 & 56.8 & 33.3 \\
$\mathrm{~L}_{25} \mathrm{RPU}$ & 25 & 155 & 2.0 & 307 & 55.7 & 34.0 \\
$\mathrm{~L}_{30} \mathrm{RPU}$ & 30 & 157 & 2.1 & 307 & 54.5 & 32.9 \\
\hline
\end{tabular}

TGA, RPU, and LRPU refer to thermogravimetric analysis, rigid polyurethane, and lignosulfonate-based rigid polyurethane, respectively

${ }^{\mathrm{a}} T_{\max 1}$ and $T_{\max 2}$ refer to the maximum degradation temperature at the first degradation step and the second degradation step, respectively. Mass loss 1 and Mass loss 2 refer to the mass loss at the first step and second step, respectively. The char was obtained at $700{ }^{\circ} \mathrm{C}$ from TGA curves 
The char yield is a critical factor in flame retardant performance during combustion. Lignin aromatic chemical structure is able to give a very high char yield [20]. The char yield increased after lignosulfonate addition (Table 1), suggests that lignosulfonate contributes to the formation of char during thermal decomposition process due to the native carbon-carbon bonds, aromatic structure and the fact that lignosulfonate molecules easily condense when heated in nitrogen $[7,21]$.

\section{The effect of lignosulfonate contents on flame retardancy of LRPU foams}

LOI is the minimum oxygen concentration (vol\%) which would support the combustion of a certain material, so the higher LOI value represents the better flame retardancy. In Fig. 2, the results showed that the LOI values increased with increasing lignosulfonate addition, indicating the enhancing effect on flame retardancy by lignosulfonate. Lignosulfonate is a natural macromolecule with substantial aromatic structures, and the LOI value increased with increasing lignosulfonate contents, indicating that lignosulfonate has a certain degree of flame retardancy due to lignosulfonate aromatic structure and its native carbon-carbon bonds helping to promote char formation. The result is in accord with the Chirico et al. [20], who reported that lignin played as fire retardant for PP.

$\mathrm{CCT}$ is used to monitor heat release rate during combustion. Low values of heat release rate (HRR) and total heat release (THR) normally indicate improved flame retardancy [5, 22]. The HRR and THR values of RPU and LRPU foams showed similar trends, which HRR and THR decreased with lignosulfonate addition to $20 \%$, and further loading of lignosulfonate showed increasing those values (Fig. 3). It can be observed that HRR and THR values of $\mathrm{L}_{20} \mathrm{RPU}$ were comparable to $\mathrm{L}_{15} \mathrm{RPU}$. The HRR value decreased from $46 \mathrm{~kW} / \mathrm{m}^{2}$

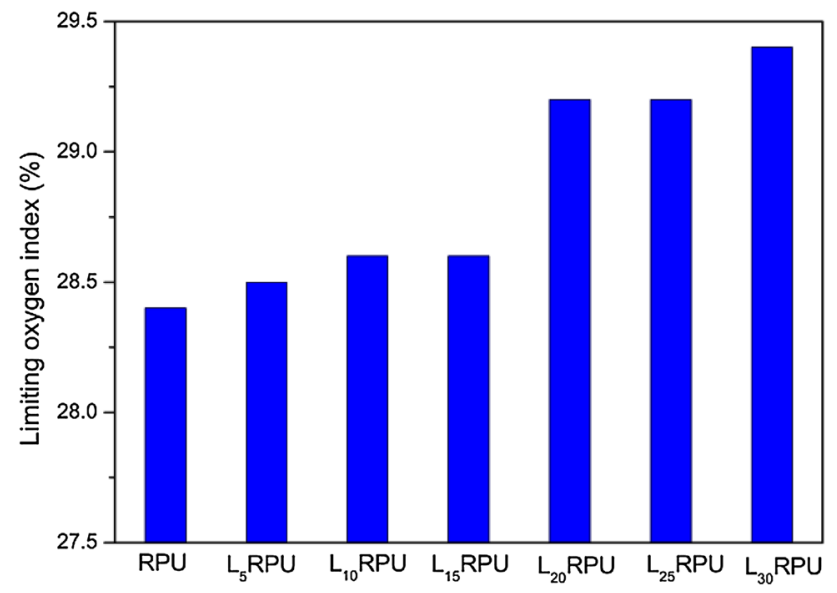

Fig. 2 LOI values of RPU and LRPU foams

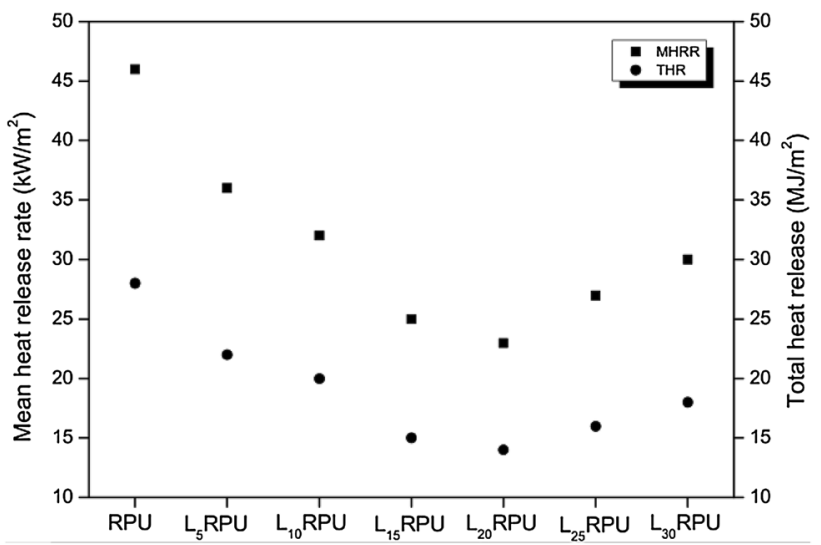

Fig. 3 Mean heat release rate (MHRR) and THR values of RPU and LRPU foams

of RPU to $23 \mathrm{~kW} / \mathrm{m}^{2}$ of $\mathrm{L}_{20} \mathrm{RPU}$ and $25 \mathrm{~kW} / \mathrm{m}^{2}$ of $\mathrm{L}_{15} \mathrm{RPU}$, and THR value decreased from $28 \mathrm{MJ} / \mathrm{m}^{2}$ of RPU to $14 \mathrm{MJ} /$ $\mathrm{m}^{2}$ of $\mathrm{L}_{20} \mathrm{RPU}$ and $15 \mathrm{MJ} / \mathrm{m}^{2}$ of $\mathrm{L}_{15} \mathrm{RPU}$, respectively.

The effect heat combustion (EHC) reflects the burning degree of the combustible and volatile gas in the gas phase. The EHC value follows the same trend as HRR and THR, which the value was the lowest at $20 \%$ lignosulfonate loading and further increasing lignosulfonate replacement ratio results increasing EHC values (Table 2).

Cone calorimeter apparatus also allows to measure the carbon monoxide $(\mathrm{CO})$ production which is considered the major cause of victims during fire [22]. In a real fire scenario, the escape time plays a fundamental role; therefore, the longer the time-to-peak CO generation, the better the material. There is no significant difference observed the $\mathrm{CO}$ release due to the lignosulfonate addition (Table 2). However, the presence of lignosulfonate very effective in the time-to-peak $\mathrm{CO}$ production $\left(T_{\mathrm{PCO}}\right)$, the $\mathrm{L}_{15} \mathrm{RPU}$ foam postponed $96 \mathrm{~s}$ than that of pure DEG RPU foam, suggesting that lignosulfonate would be mainly act at condensed phase with higher char production.

The average mass loss rate (AMLR) measured by cone calorimeter was decreased with increasing of lignosulfonate contents (Table 2). It is also confirmed by derivative thermogravimetric (DTG) analysis data, which the char yield increased with increasing of lignosulfonate contents.

\section{The effect of lignosulfonate-to-APP ratio on intumescent flame retardancy of LRPU foams}

It is suggested that a suitable phosphorus/nitrogen/carbon (P/N/C) ratio in the IFR system is very important for its flame retardancy [4]. In this study, the proportion of lignosulfonate (carbonization agent)-to-APP (acid and blowing agent) ratios was studied to investigate the flame retardancy of lignosulfonate and APP combination in LRPU foams. As 
Table 2 Detail data of cone calorimeter measurements of RPU and LRPU foams

\begin{tabular}{llllll}
\hline Sample & $\begin{array}{l}\text { Lignin contents } \\
(\%)\end{array}$ & $\mathrm{EHC}^{\mathrm{a}}(\mathrm{MJ} / \mathrm{kg})$ & $\mathrm{CO}^{\mathrm{a}}(\mathrm{kg} / \mathrm{kg})$ & $T_{\mathrm{PCO}}{ }^{\mathrm{a}}(\mathrm{s})$ & $\mathrm{AMLR}^{\mathrm{a}}(\mathrm{g} / \mathrm{s})$ \\
\hline $\mathrm{RPU}$ & 0 & 19.3 & 0.042 & 25 & 0.021 \\
$\mathrm{~L}_{5} \mathrm{RPU}$ & 5 & 17.9 & 0.042 & 120 & 0.018 \\
$\mathrm{~L}_{10} \mathrm{RPU}$ & 10 & 18.1 & 0.044 & 103 & 0.016 \\
$\mathrm{~L}_{15} \mathrm{RPU}$ & 15 & 14.7 & 0.051 & 121 & 0.015 \\
$\mathrm{~L}_{20} \mathrm{RPU}$ & 20 & 13.3 & 0.047 & 63 & 0.015 \\
$\mathrm{~L}_{25} \mathrm{RPU}$ & 25 & 18.2 & 0.043 & 39 & 0.013 \\
$\mathrm{~L}_{30} \mathrm{RPU}$ & 30 & 18.7 & 0.039 & 44 & 0.014 \\
\hline
\end{tabular}

RPU and LRPU refer to rigid polyurethane and lignosulfonate-based rigid polyurethane, respectively

${ }^{a} \mathrm{EHC}, \mathrm{CO}, T_{\mathrm{PCO}}$, and AMLR refer to the effective heat combustion, the carbon monoxide production, the time-to-peak $\mathrm{CO}$ production, and the average mass loss rate, respectively

\begin{tabular}{lllllll}
\hline Sample & $\begin{array}{l}\text { Lignin:APP } \\
\text { ratio }\end{array}$ & $T_{\max 1}\left({ }^{\circ} \mathrm{C}\right)$ & $\begin{array}{l}\text { Mass loss1 } \\
(\mathrm{wt} \%)\end{array}$ & $T_{\max 2}\left({ }^{\circ} \mathrm{C}\right)$ & $\begin{array}{l}\text { Mass loss2 } \\
(\mathrm{wt} \%)\end{array}$ & $\mathrm{Char}_{700{ }^{\circ} \mathrm{C}}(\mathrm{wt} \%)$ \\
\hline LRPU1 & $1: 1$ & 145 & 2.0 & 307 & 57.6 & 28.1 \\
LRPU2 & $1: 2$ & 145 & 2.9 & 305 & 57.0 & 28.2 \\
LRPU3 & $1: 3$ & 143 & 1.4 & 292 & 53.9 & 32.8 \\
LRPU4 & $1: 4$ & 148 & 3.2 & 297 & 54.2 & 35.3 \\
LRPU5 & $1: 5$ & 149 & 2.5 & 296 & 53.5 & 38.0 \\
\hline
\end{tabular}

TGA, LRPU, and APP refer to thermogravimetric analysis, lignosulfonate-based rigid polyurethane, and ammonium polyphosphate, respectively
Table 3 Detail data of TGA measurements of LRPU foams of different lignosulfonate-toAPP ratios

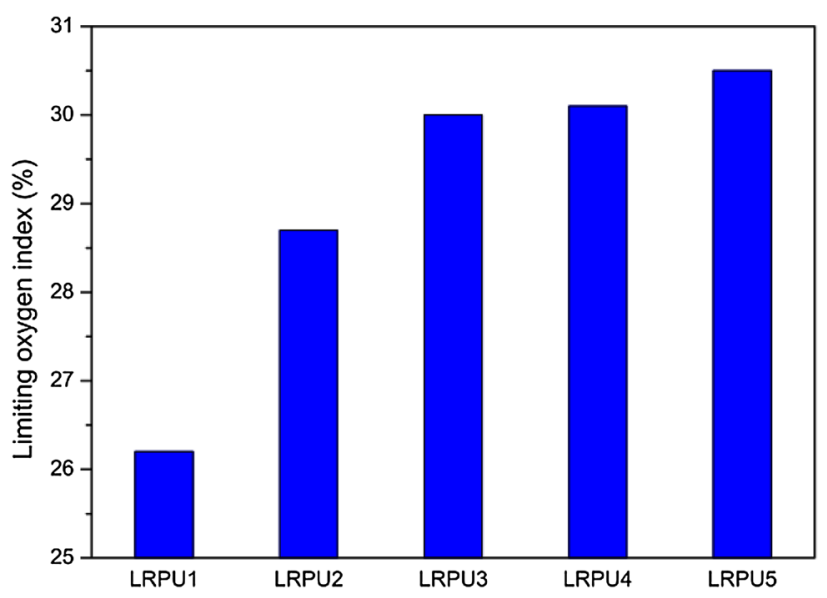

Fig. 4 LOI values of LRPU foams from different lignosulfonate-toAPP ratios

as acid and blowing agent at the same time, and lignosulfonate would be thermo-oxidized, dehydrated by the acid, act as carbonizing agent. The LOI value was $30 \%$ at lignosulfonate-to-APP ratio 1:3, and further loading APP, the LOI value grows slowly (Fig. 4). The LOI value of LRPU5 foam was 30.5\%, which meet the GB 8624-2012 standard [26] B1 grade. 


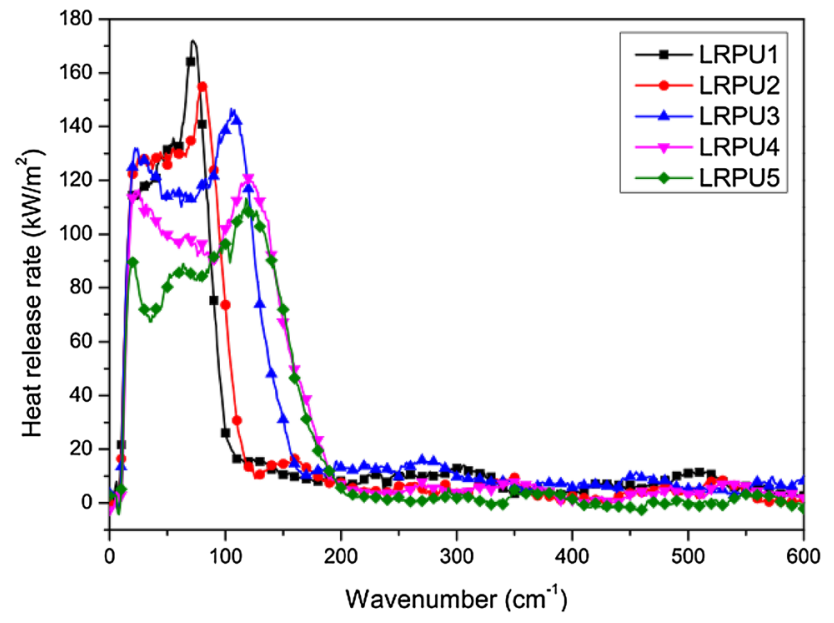

Fig. 5 HRR curves of LRPU foams of different lignosulfonate-toAPP ratios

The curves of the HRR show a significant decrease with lignosulfonate-to-APP ratio increasing (Fig. 5). The addition of APP reduced the peak HRR (PHRR) value from 172 to $113 \mathrm{~kW} / \mathrm{m}^{2}$, and postponed the time to PHRR from 72 to $118 \mathrm{~s}$ (Table 4). The interaction between lignosulfonate and APP leads to the formation of a protective surface shield able to reduce HRR value. The lower THR values were obtained from LRPU1 foam and LRPU5 foam, while LRPU3 foam gave rise to the highest THR value, indicating that $\mathrm{P} / \mathrm{N} / \mathrm{C}$ ratio in the IFR system is very important. THR value of LRPU5 foam was $14.2 \mathrm{MJ} / \mathrm{m}^{2}$, which fulfills the GB 8624-2012 standard [26] B1 grade of burning behavior of building materials and products.

The lowest EHC value was observed from LRPU1 foam, suggesting that APP mainly acts at condensed phase by formation of char structure [23-25]. In addition, the results coincide with the TGA conclusion which the highest char yield was obtained from LRPU5 foam (Table 3 ).

The toxicity of gaseous products evolving during combustion is an essential parameter which can be estimated using a cone calorimeter. $\mathrm{CO}$ is main toxicity gas during fire accident. During combustion, formulation with higher lignosulfonate-to-APP ratio yields less smoke. The increasing of APP dosage reduced the mean CO production from 0.076 to $0.024 \mathrm{~kg} / \mathrm{kg}$, and decreased both total smoke rate (TSR) and total smoke production (TSP) from 398 to $291 \mathrm{~m}^{2} / \mathrm{m}^{2}$ and from 3.5 to $2.6 \mathrm{~m}^{2}$, respectively, suggesting that APP does not only release ammonia to dilute toxicity gas, but also create a protective layer resulting decreasing smoke and toxicity gas production.

\section{Conclusion}

The char yield increased with increasing lignosulfonate contents, due to lignosulfonate aromatic structure and its native carbon-carbon bonds helping to promote char formation. The average mass loss rate (AMLR) measured by cone calorimeter decreased with increasing of lignosulfonate contents. Lignosulfonate increases thermal stability of RPU foams and $\mathrm{L}_{15} \mathrm{RPU}$ foam gives rise to the best thermal stability. The LOI values increased with increasing lignosulfonate addition, indicating that lignosulfonate has a certain degree of flame retardancy. The HRR and THR showed lower values at 15-20\% lignosulfonate loading and further increasing lignosulfonate replacement ratio results increasing HRR and THR values. The presence of lignosulfonate very effective in $T_{\mathrm{PCO}}$, the $\mathrm{L}_{15} \mathrm{RPU}$ foam postponed $96 \mathrm{~s}$ than that of pure DEG RPU foam, suggesting that lignosulfonate would be mainly act at condensed phase with higher char production.

The mass loss gradually decreases with increasing APP addition, and the highest char yield was obtained from LRPU5 foam, due to the protection action of char layer from the degradation of APP. The LOI value increased with increasing APP addition, the LOI value is $30 \%$ at the lignosulfonate-to-APP ratio of 1:3, and further increase the ratio, the LOI value grows slowly. With increasing the lignosulfonate-to-APP ratio, the mean HRR value reduced and the time to maximum HRR postponed significantly. The interaction between lignosulfonate and APP leads to the formation of a protective surface shield able to reduce HRR value. The

Table 4 Detail data of LRPU foams of different lignosulfonate-to-APP ratios from cone calorimeter

\begin{tabular}{lllllllll}
\hline Sample & $\begin{array}{l}\text { Lignin:APP } \\
\text { ratio }\end{array}$ & $\begin{array}{l}\mathrm{PHRR}^{\mathrm{a}} \\
\left(\mathrm{kW} / \mathrm{m}^{2}\right)\end{array}$ & $T_{\mathrm{PHRR}}{ }^{\mathrm{a}}(\mathrm{s})$ & $\mathrm{THR}^{\mathrm{a}}\left(\mathrm{MJ} / \mathrm{m}^{2}\right)$ & $\mathrm{TSR}^{\mathrm{a}}\left(\mathrm{m}^{2} / \mathrm{m}^{2}\right)$ & $\mathrm{TSP}^{\mathrm{a}}\left(\mathrm{m}^{2}\right)$ & $\mathrm{MCO}(\mathrm{kg} / \mathrm{kg})$ & $\mathrm{MEHC}(\mathrm{MJ} / \mathrm{kg})$ \\
\hline LRPU1 & $1: 1$ & 172 & 72 & 14.8 & 398 & 3.5 & 0.076 & 16.2 \\
LRPU2 & $1: 2$ & 156 & 81 & 14.7 & 443 & 3.9 & 0.066 & 16.1 \\
LRPU3 & $1: 3$ & 147 & 105 & 19.3 & 491 & 4.3 & 0.046 & 16.9 \\
LRPU4 & $1: 4$ & 121 & 120 & 17.3 & 410 & 3.6 & 0.036 & 15.4 \\
LRPU5 & $1: 5$ & 113 & 118 & 14.2 & 291 & 2.6 & 0.024 & 14.5 \\
\hline
\end{tabular}

LRPU and APP refer to lignosulfonate-based rigid polyurethane and ammonium polyphosphate, respectively. ${ }^{\text {a: }}$ PHRR and $T_{\mathrm{PHRR}}$ refer to the peak heat release rate and the time-to-peak heat release rate, respectively. THR, TSR, TSP, MCO, and MEHC refer to the total heat release, the total smoke rate, the total smoke production, the mean $\mathrm{CO}$ production, and the mean effective heat combustion, respectively 
LRPU5 foam gives rise to the lowest EHC value, less smoke, and $\mathrm{CO}$ production. The best fire retardancy is obtained from LRPU5 foam, which the LOI and burning behavior meet the GB 8624-2012 standard [26] B1 grade.

Acknowledgements The study was supported by the National Natural Science Foundation of China (No. 31670597), International Cooperative Research Project (No. 2016YFE0125800), and Zhejiang Xinmiao Talents Project (No. 2017R412045).

\section{Compliance with ethical standards}

Conflict of interest The authors declare that they have no conflict of interest.

Ethical approval All procedures performed in studies involving human participants were in accordance with the ethical standards of the institutional.

\section{References}

1. Luo F, Wu K, Lu M (2016) Enhanced thermal stability and flame retardancy of polyurethane foam composites with polybenzoxazine modified ammonium polyphosphates. RSC Adv 6:13418-13425

2. Lin H, Yan H, Liu B, Wei L, Xu B (2011) The influence of $\mathrm{KH}-550$ on properties of ammonium polyphosphate and polypropylene flame retardant composites. Polym Degrad Stabil 96:1382-1388

3. Ruban L, Zaikov G (2001) Importance of intumescence in polymers fire retardancy. Intern J Polymeric Mater 48:295-310

4. Wu K, Shen MM, Hu Y (2011) Synthesis of a novel intumescent flame retardant and its flame retardancy in polypropylene. J Polym Res 18:425-433

5. Doğan M, Y1lmaz A, Bayramlı E (2010) Synergistic effect of boron containing substances on flame retardancy and thermal stability of intumescent polypropylene composites. Polym Degrad Stabil 95:2584-2588

6. Sarkanen KV, Ludwig CH (1971) Lignins: occurrence, formation, structure and reactions. Wiley Interscience, New York, p 915

7. Hirose $S$ (2015) Novel epoxy resins with unsaturated ester chains derived from sodium lignosulfonate. Macromol Symp 353:31-38

8. Ferry L, Dorez G, Taguet A, Otazaghine B, Lopez-Cuesta JM (2015) Chemical modification of lignin by phosphorus molecules to improve the fire behavior of polybutylene succinate. Polym Degrad Stabil 113:135-143

9. Canetti M, Bertini F, Chirico AD, Audisio G (2006) Thermal degradation behaviour of isotactic polypropylene blended with lignin. Polym Degrad Stabil 91:494-498

10. Canetti M, Bertini F (2007) Supermolecular structure and thermal properties of poly (ethylene terephthalate)/lignin composites. Compos Sci Technol 67:3151-3157

11. Yu Y, Fu S, Song P, Luo X, Jin Y, Lu F, Wu Q, Ye J (2012) Functionalized lignin by grafting phosphorus-nitrogen improves the thermal stability and flame retadancy of polypropylene. Polym Degrad Stabil 97:541-546

12. Song P, Cao Z, Fu S, Fang Z, Wu Q, Ye J (2011) Thermal degradation and flame retardancy properties of ABS/lignin: effects of lignin content and reactive compatibilization. Thermochim Acta 518:59-65

13. Bertini F, Canetti M, Cacciamani A, Elegir G, Orlandi M, Zoia L (2012) Effect of ligno-derivatives on thermal properties and degradation behavior of poly(3-hydroxybutyrate)-based biocomposites. Polym Degrad Stabil 97:1979-1987

14. Hatakeyama H, Hatakeyama T (2015) Green polyurethanes and biocomposites. Molecular design and characterization. Nova publishers, New York, p. 214

15. Laurichesse $S$, Averous L (2013) Chemical modification of lignins: towards biobased polymers. Prog Polym Sci 39:1266-1290

16. Mahmood N, Yuan ZS, Schmidt J, Xu CB (2016) Depolymerization of lignins and their applications for the preparation of polyols and rigid polyurethane foams: a review. Renew Sust Energ Rev 60:317-329

17. GB/T 2406.2-2009 (2010) Plastics-determination of burning behaviour by oxygen index-part 2: ambient-temperature test (in Chinese). Standardization Administration of the People's Republic of China, Beijing, p 9

18. ISO5660-1:2015 (2015) Reaction-to-fire tests-heat release, smoke production and mass loss rate-part 1: heat release rate (cone calorimeter method). International Organization for Standardization, Geneva, pp 11-14

19. ASTM E1354-16a (2016) Standard test method for heat and visible smoke release rates for materials and products using an oxygen consumption calorimeter. ASTM International, Pennsylvania, pp 21-24

20. Chirico AD, Armanini M, Chini P, Cioccolo G, Provasoli F, Audisio G (2003) Flame retardants for polypropylene based on lignin. Polym Degrad Stabil 79:139-145

21. Zhu H, Peng Z, Chen Y, Li G, Wang L, Tang Y, Pang R, Khan Z, Wan $P$ (2014) Preparation and characterization of flame retardant polyurethane foams containing phosphorus-nitrogen-functionalized lignin. Rsc Adv 4:55271-55279

22. Checchin M, Cecchini C, Cellarosi B, Sam FO (1999) Use of cone calorimeter for evaluating fire performances of polyurethane foams. Polym Degrad Stabil 64:573-576

23. Levchik SV, Weil ED (2004) Thermal decomposition, combustion and fire-retardancy of polyurethanes-a review of the recent literature. Polym Int 53:1585-1610

24. Grassie N, Mendoza PGA (1985) Thermal degradation of polyether-urethanes: part 4-Effect of ammonium polyphosphate on the thermal degradation of polyether urethanes prepared from methylene bis(4-phenylisocyanate) and low molecular weight poly(ethylene glycols). Polym Degrad Stabil 11:145-166

25. Grassie N, Mendoza PGA (1985) Thermal degradation of polyether-urethanes: 5. Polyether urethanes prepared from methylene bis(4-phenylisocyanate) and high molecular weight poly (ethylene glycols) and the effect of ammonium polyphosphate. Polym Degrad Stabil 11:359-379

26. GB 8624-2012 (2013) Classification for burning behavior of building materials and products (in Chinese). Standardization Administration of the People's Republic of China, Beijing, p 20 